\title{
Assessment of Knowledge andSkills of CPRamong Internsof two Medical Colleges in North-East India
}

\author{
Brogen Singh Akoijam ${ }^{1}$, Amrita Sougaijam ${ }^{2}$, Lalngaihawmi Chhangte ${ }^{2}$, \\ Priscilla Kayina ${ }^{3}$, Tomcha Khuman ${ }^{4}$, Devandiran $\mathrm{RS}^{2}$ \\ ${ }^{I}$ (Professor, Department of Community Medicine, Regional Institute of Medical Sciences, Imphal, \\ Manipur, India) \\ ${ }_{2}^{2}$ (PGT, Department of Community Medicine, Regional Institute of Medical Sciences, Imphal, Manipur, India) \\ ${ }_{3}^{3}$ (Assistant Professor, Jawaharlal Nehru Institute of Medical Sciences,,Imphal, Manipur, India) \\ ${ }^{4}$ (Deputy Director, Manipur Health Services, India)
}

\begin{abstract}
:
Introduction: Cardiopulmonary Resuscitation $(C P R)$ is an important life-saving first aid skill, practiced throughout the world.Over time, resuscitation skills have evolved into a proper protocol, which involves CPR commonly known as BLS. Invented in 1960, CPR is a simple but effective procedure that allows almost anyone to sustain life in the early critical minutes after cardiac and respiratory arrest. BLS includes both prompt recognition and immediate support of ventilation and circulation in case of respiratory or cardiac arrest..CPR provided immediately after sudden cardiac arrest can effectively increase the victim's chances of survival.So, keeping this in mind, the study was undertaken to determine the knowledge and skills about cardiopulmonary resuscitation among interns.
\end{abstract}

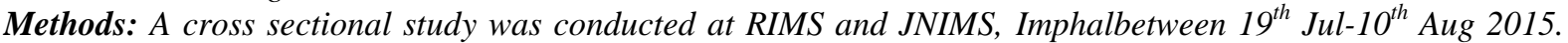
Eighty interns posted at the Community Medicine Department were included in the study. A self-administered questionnaire and assessment of skills were used for data collection. Data were analyzed using descriptive statistics such as frequencies and percentages. Chi-square test was used for analysis. $P$ value of $<0.05$ was considered as statistically significant.

Results: More than half of them knew when to start CPR but didn't know when to put a victim in a recovery position or how to open the airway. Nearly three fourth of them didn't know when they were suppose tostop CPR. Majority of them didn't know the correct site for chest compression. Very few of them checked for response and breathing and most of the participants had incorrect positioning while performing it. None of the participants knew how to give rescue breaths

Conclusions: Most of the interns were found to have inadequate knowledge and skills regarding CPR. Training programmes will be needed to maximize knowledge/skills so as to save more lives with this valuable maneuver.

Keywords: CPR, knowledge, Interns

\section{Introduction}

Cardiopulmonary arrest is a major public health problem ${ }^{1}$ and many patients sustained cardiac arrest in two years. ${ }^{2}$ Approximately 4280 out of every one lakh people die every year from SCA in India alone. ${ }^{3}$ Cardiopulmonary arrest is one of the most common unfortunate incidents that may occur in and out of the health facilities. ${ }^{4,5}$ Cardiopulmonary resuscitation (CPR) is a lifesaving technique ${ }^{6}$ and consists of chest compression and rescue breathing. ${ }^{7}$ The quality of cardiopulmonary resuscitation depends on the sufficiency of the knowledge of health professionals and facilities. ${ }^{8,9}$ Increasing survival of patients from cardiopulmonary arrest requires improvement in resuscitation education. ${ }^{10,11}$ It is not surprising to note that even junior doctors at certain hospitals cannot perform the first aid skills satisfactorily. ${ }^{12} \mathrm{BLS}$ requires nothing as far as resources are concerned and its importance is undeniable. Knowledge of BLS and practice of the simple CPR techniques and maneuvers ensures the survival of the patient long enough till experienced medical help arrives and in most cases is itself sufficient for survival. Proper practice of the techniques enables a person to effectively resuscitate a victim. Ideally, everyone should know BLS and CPR but its awareness to medical graduates is invaluable. Newly qualified doctors are expected to take part in resuscitation from their first day.

Most of the SCD events occurs out-of-hospital before any contact with health professionals. It ${ }^{\text {es }}$ estimated that more than $70 \%$ of ventricular fibrillation victims die before reaching the hospital. ${ }^{13}$ Less than $1 \%$ of the general population can perform it effectively. It has estimated that if $15-20 \%$ could perform BLS, out of hospital mortality could be significantly reduced. ${ }^{14}$ The ideal situation would be to train the whole population, but it is impossible in a resources limited country like India. So, it limits trainings to be targeted to certain groups e.g. medical and police personnels etc. A study conducted in India showed that the knowledge of nursing students and interns about basic life support (BLS) was very poor. ${ }^{15}$ Studies on BLS have been rarely conducted 
among interns in this part of the country. So, keeping this in mind, this cross sectional study was carried out to assess the knowledge about CPR among interns in two colleges of Manipur.

\section{Materials And Methods}

A cross sectional study was carried out from $19^{\text {th }}$ July to $10^{\text {th }}$ August 2015 among interns of RIMS and JNIMS, Manipur. There were 111 and 98 interns in RIMS and JNIMS respectively at the time of study period. All the interns of the respective colleges who were doing internship in the department of Community Medicine during this period and who were willing to participate were taken eligible for the study. Those who were on leave were excluded.

The study intended to cover all the interns doing internship during the study period.A self-administered questionnaire containing socio-demographic and knowledge regarding CPR was used. A checklist was also used to assess the skills of CPR and was done through observation and video recording. All the participants were requested to come to Community Medicine Department, RIMS for data collection. After taking a verbal consent, they were asked to fill up the questionnaire in 15 minutes under observation. Assessment of skills on CPR were done individually for each participant using a mannequin. Two investigators (BA and AS) were involved in doing this, one for observing them while doing it and the other for recording the act. If any disagreement arises between the two, opinion of the third investigator (AC) was taken to come to a consensus. Data collected were checked for completeness and consistency and were analysed using IBM SPSS 21 for Windows. Descriptive statistics like frequency and percentage were used for analysis. Chi-square tests were used to see the association between the variables ( knowledge on CPR with gender) and p- value of $<0.05$ was considered as statistically significant. Approval was obtained from the Institutional Ethics Committee RIMS. Written permission from all the participating college authorities and verbal consent from all the participants were obtained. Confidentiality was maintained as identifiers like names were masked and access to data were restricted only to the investigators.

\section{Results}

A total of 80 participants took part in this study.59 from RIMS and the remaining from JNIMS. More than half $(55 \%)$ of them were females. Less than half on an average knew about BLS, AED and EMS (65\%, $12.5 \%$ and $25 \%$ respectively, Fig. 1 ).

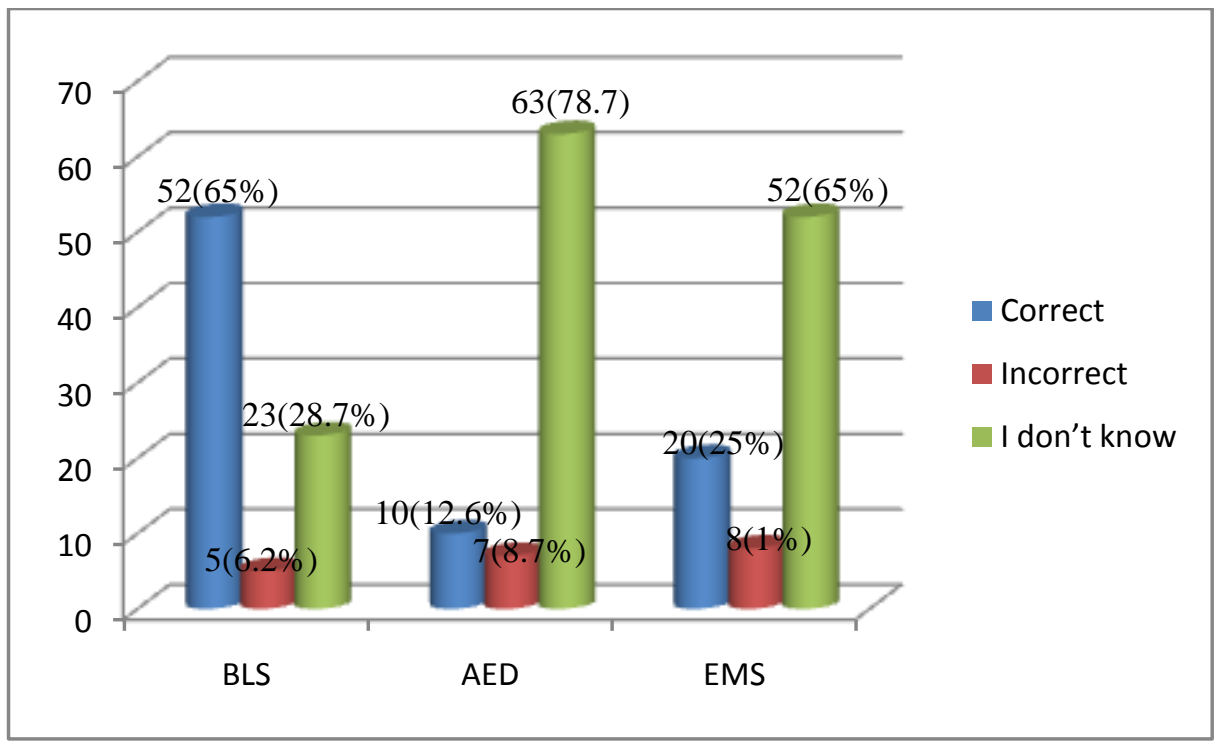

Fig 1: Response to full forms of BLS, AED and EMS $(\mathrm{N}=80)$

Six out of ten knew when to start CPR but only few knew when to put a victim in a recovery position $(11.2 \%)$ or how to open the airway $(17.5 \%)$. Around thirty percent of them didn't know when to keep the victim in recovery position and nearly three fourth of them didn't know of the conditions when they were suppose to stop CPR(Table 1). 
Table 1: Distribution of participants regarding knowledge on CPR. (N=80)

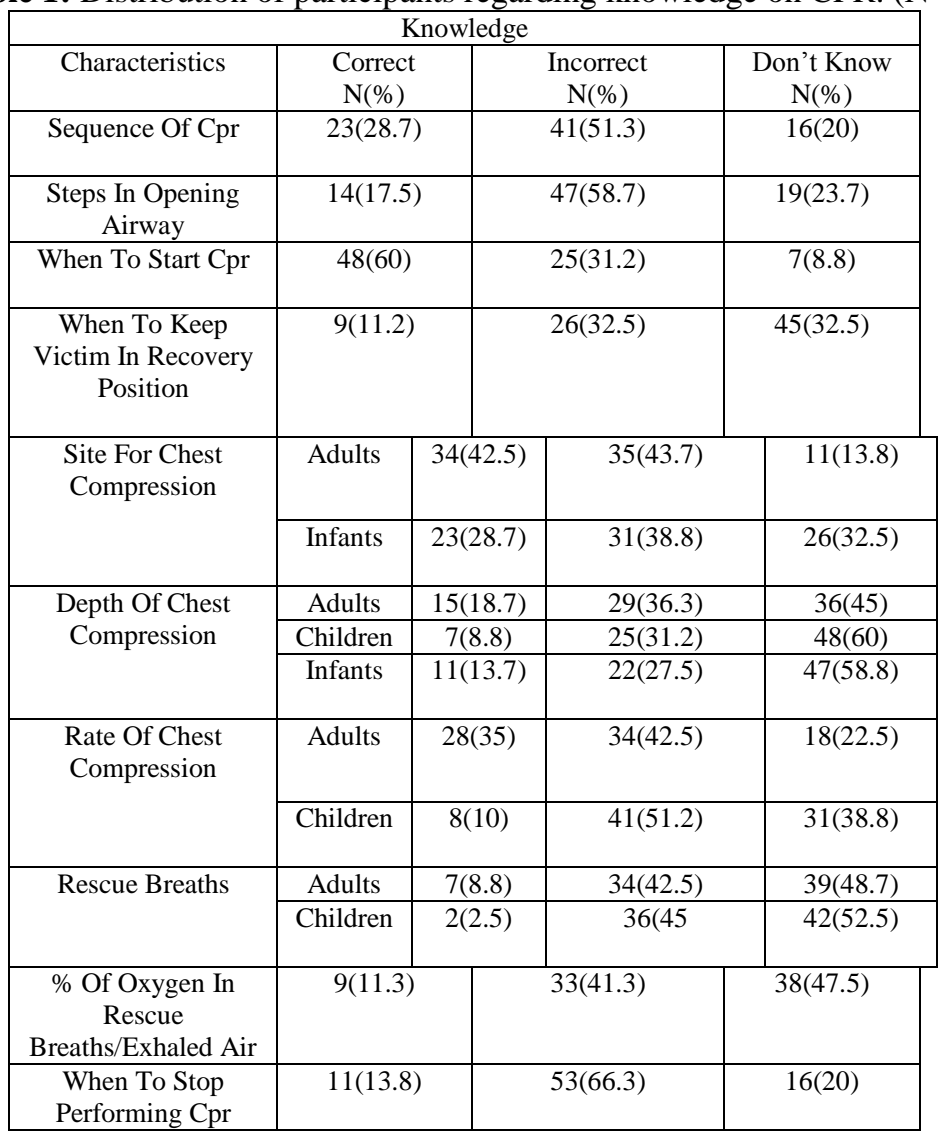

Very few of them checked for response (3.8\%) and breathing $(8.8 \%)$ and most of the participants had incorrect position while performing CPR. Almost all of the participants who performed rescue breaths, gave it wrongly or was left undone (Table 2).

Table 2: Distribution of participants on skills of CPR. $(\mathrm{N}=80)$

\begin{tabular}{|c|c|c|c|c|}
\hline \multicolumn{5}{|c|}{ Critical Performance Criteria (Skills) } \\
\hline \multicolumn{2}{|c|}{ Criteria } & $\begin{array}{c}\text { Correct } \\
\mathrm{N}(\%)\end{array}$ & $\begin{array}{c}\text { Incorrect } \\
\mathrm{N}(\%)\end{array}$ & $\begin{array}{c}\text { Not Done } \\
\mathrm{N}(\%)\end{array}$ \\
\hline \multicolumn{2}{|c|}{ Check For Response(N=21) } & $3(3.8)$ & $18(22.4)$ & $59(73.8)$ \\
\hline \multicolumn{2}{|c|}{ Check For Breathing $(\mathrm{N}=25)$} & $7(8.8)$ & $18(22.4)$ & $55(68.8)$ \\
\hline \multicolumn{5}{|c|}{ Steps Of Cpr } \\
\hline \multirow[t]{5}{*}{ Position } & Rescuer & $27(33.8)$ & $53(66.3)$ & - \\
\hline & Knee & $27(33.8)$ & $53(66.3)$ & - \\
\hline & Hip & $21(26.3)$ & $59(73.8)$ & - \\
\hline & Elbow & $12(15)$ & $68(85)$ & - \\
\hline & Movement & $8(10)$ & $72(90)$ & - \\
\hline \multirow[t]{4}{*}{ Chest Compression } & Site & $45(56.3)$ & $35(43.8)$ & - \\
\hline & Hand Position & $12(15)$ & $68(85)$ & - \\
\hline & Rate & $5(6.3)$ & $75(93.8)$ & - \\
\hline & Depth & $8(10)$ & $72(90)$ & - \\
\hline \multicolumn{5}{|c|}{ Rescue Breaths } \\
\hline \multirow[t]{2}{*}{ Position(N=53) } & Rescuer & $14(17.5)$ & $66(82.5)$ & - \\
\hline & Victim & $7(8.8)$ & $44(55)$ & $29(36.3)$ \\
\hline \multicolumn{2}{|c|}{ Nose Pinched(N=17) } & $9(11.3)$ & $8(10)$ & $63(78.8)$ \\
\hline \multicolumn{2}{|c|}{ Mouth Well Covered(N=35) } & $1(1.3)$ & $34(42.5)$ & $45(56.3)$ \\
\hline \multicolumn{2}{|c|}{ Chest Raising(N=35) } & $1(1.3)$ & $34(42.5)$ & $45(56.3)$ \\
\hline
\end{tabular}

As compared to males, females had more knowledge on steps of opening the airway and was found to be statistically significant $(P=0.03$, Table 3$)$. 
Assessment of Knowledge and Skills of Cpr among Internsof Two Medical Colleges in ....

Table 3: Association between knowledge and gender. $(\mathrm{N}=80)$

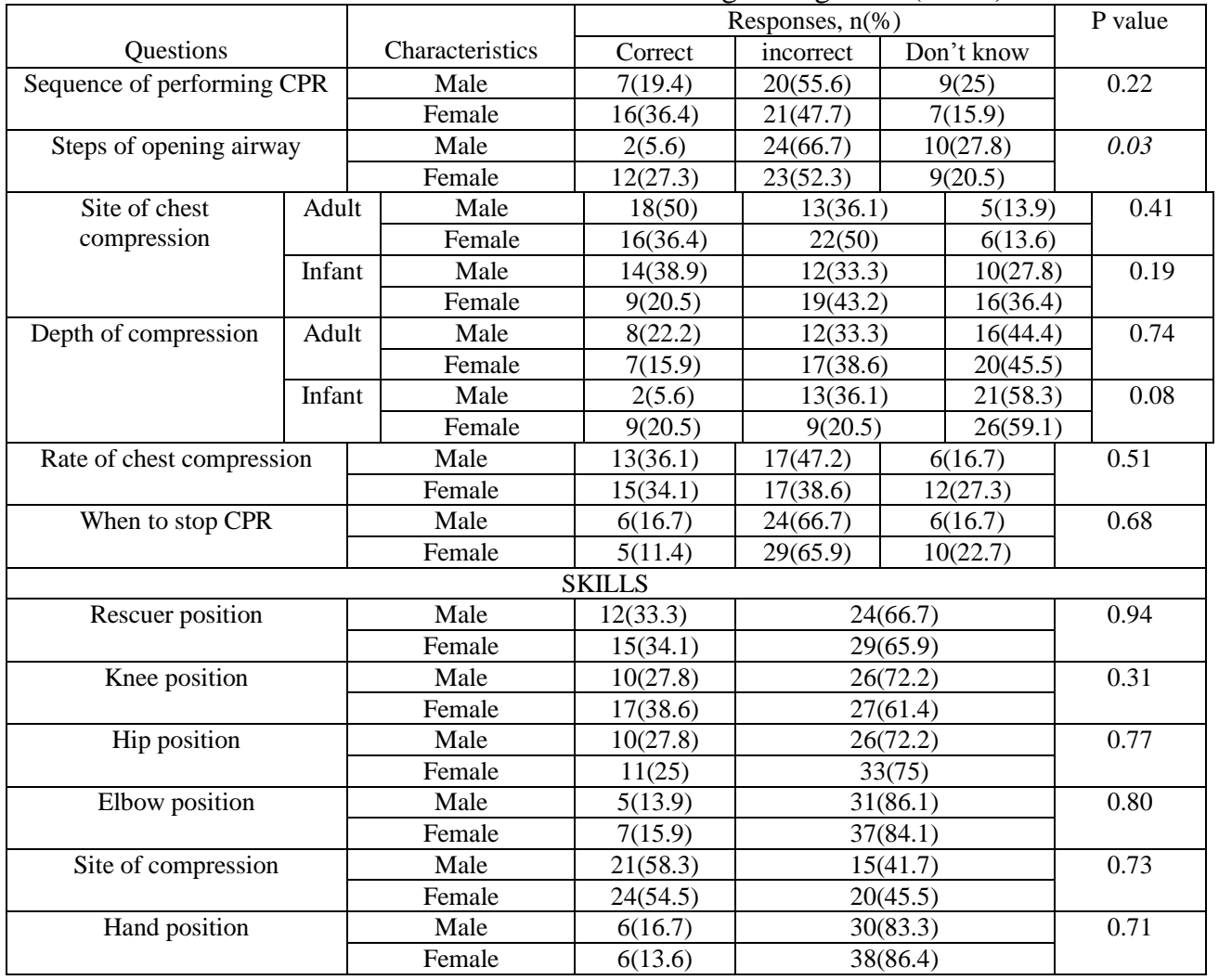

\section{Discussion}

This study showed that a small percentage of interns knew how to carry out CPR.The level of knowledge about CPR was below fifty percent on an average among them. It also identified the key areas in which first aid knowledge was lacking. It seems that without a formal CPR training, interns may not acquire the confidence to correctly perform the procedure.

Our study showed that less than half of the participants had heard about BLS/AED/EMS (Fig.1). Several other studies ${ }^{15,16,17,18}$ have shown similar findings like this regarding inadequate knowledge of CPR. Similar findings were observed in another study conducted by Kumar $\mathrm{H}$ et al ${ }^{19}$ among under graduate medical students in coastal South India in 377 students where majority (84.6\%) had heard of BLS/CPR. In another study by Zaheer $\mathrm{H}$ et $\mathrm{al}^{20}$ conducted at Jinnah Medical and Dental College., $57.3 \%$ had no knowledge, among those $34 \%$ had heard BLS from somewhere, $22.9 \%$ had some knowledge out of which $50 \%$ had heard about it. There is thus a need for formal first aid training to be introduced in the medical curriculum..

Less than fifty percent of participants had any knowledge on performing CPR (sequence/steps/when to start CPR) as shown in table 1 . This observation is mirrored in another study ${ }^{19}$ done among medical students where only $30.6 \%$ of the participants could give the correct order of performing CPR. This means that, not only is first aid training required in our college, moreover, it has to be reinforced periodically with refresher training workshops in first aid

Skills regarding CPR was observed to be less than fifty percent on an average (table 2). Another study ${ }^{20}$ done among medical students in 2006 showed similar findings having less number of students having skills for BLS $(21 \%)$.One explanation could be that without proper knowledge of the subject it is impossible to have skills of the same. And even if its there, it can deteriorate and lose confidence over a period of time. This is possible only if the training is introduced at the beginning of the curriculum and to have repeated training over time.

There was no difference between males and females regarding knowledge on CPR (table 3). Similar findings were seen in a study conducted by Ralapanawa DM et al. ${ }^{21}$ Another study done by $\mathrm{Ravari}_{\mathrm{H}}$ et al ${ }^{22}$ among medical interns showed that males were more educated $(\mathrm{p}=0.041)$ than females. On the contrary, proper CPR information was higher among females(87\%) than males $(61 \%)$ in a study done among school students in Riyadh by Alanazi et $\mathrm{al}^{23}$.

The main strength of our study was that questionnaire was answered by the respondents solely under supervision, thus discussion among the students might not occur which show the honesty of the answers. 
The only limitation faced was that we adopted convenience method of sampling. Moreover, as the study was performed in the two medical colleges, the findings in this study cannot be generalized to all colleges in different parts of India.

\section{Conclusion}

From this study, it can be concluded that lack of awareness regarding BLS among medical students is a serious issue that needs to be addressed promptly. The level of knowledge about first aid was not good among most of the participants. The study also identified key areas in which first aid knowledge was lacking and further identified the need for introducing formal first aid training classes for medical students so that the trained students are competitive enough to provide first aid independently and spontaneously in real life situations. This should be backed up with periodic refresher training as level of knowledge in first aid skills fades with time. So, keeping this in mind, training in advanced life support should become a standardized and mandatory component of all medical school curriculum. Similar studies can be done (i) on a larger scale, ii) More research is warranted in our set up also involving other medical personnel and to determine an appropriate and efficient course design and iii)The findings necessitates the importance of establishing a curriculum for CPR.

\section{Acknowledgments}

The authors would like to thank the staff members of Community Medicine department, JNIMS and their interns for their support and cooperation. Also the RIMS interns posted during that period to our Community Medicine department for their help during data collection.

\section{References}

[1]. Chugh SS, Reinier K, Teodorescu C, Evanado A, Kher E, Samara AM, et al. Epidemiology of sudden cardiac death: clinical and research implications. ProgCardiovasc Dis 2008;51(1):213-28.

[2]. Peberdy MA, Kaye W, Ornato JP, Larkin LG, Nadkarni V, Mancini EM, et al. Cardiopulmonary resuscitation of adults in the hospital: A report of 14720 cardiac arrests from the national registry of cardiopulmonary resuscitation. Resuscitation 2003;58(1):297-308

[3]. James JV. A study to assess the effectiveness of structured teaching programme regarding knowledge on BLS among Pre University college students in selected schools of Bangalore [dissertation]. Bangalore: Karnataka Univ. ;2006.

[4]. Shultz JJ, Lurie KG. Variations in cardiopulmonary resuscitation techniques: past, present and future. Can J Cardiol 1995;11(1):873-80.

[5]. Heller RF, Steele LR, Fisher DJ, Alexander MH, J Dobson JA. Success of cardiopulmonary resuscitation after heart attack in hospital and outside hospital. BMJ 1995;311(1):1332-6.

[6]. Mayo Clinic. Cardiopulmonary resuscitation (CPR): First aid. 2005; [18 screens]. Available at: http://www.mayoclinic.org> art20056600. Accessed October 18, 2016.

[7]. Iwami T, Kitamura T, Kawamura T, Mitamura H, Nagao K, Takayama M, et al. Cheat compression-only cardiopulmonary resuscitation for out-of-hospital cardiac arrest with public-access defibrillation: a nationwide cohort study. Circulation 2012;126(24):2844-51

[8]. Luo XR, Zhang HL, Chen GJ, Ding WS, Huang L. Active compression-decompression cardiopulmonary resuscitation (CPR) versus standard CPR for cardiac arrest patients: a meta analysis. World J Emerg Med 2013;4(1):266-72.

[9]. Bhanji F, Mancini ME, Sinz E, Rodgers DL, McNeil MA, Hoadley TA, et al. Part 16: education, implementation, and teams: 2010 American Heart Association Guidelines for Cardiopulmonary Resuscitation and Emergency Cardiovascular Care. Circulation 2010;122(3):920-33.

[10]. Sutton RM, Niles D, Nysaether J, Abella BS, Arbogast KB, Nishisaki A, et al. Quantitative analysis of CPR quality during inhospital resuscitation of older children and adolescents. Pediatrics 2009;124(1):494-9.

[11]. Peters R, Boyde M. Improving survival after in-hospital cardiac arrest: the Australian experience. Am J Crit Care 2007;16(3):240-6.

[12]. Tan EC, Severien I, Metz JC, Berden HJ, Biert J. First aid and basic life support of junior doctors: A prospective study in Nijmegen, the Netherlands. Med Teach 2006;28(1):189-92.

[13]. Patidar AB, Sharma A. Attitude of School Children towards Basic Life Support in Punjab, India. IJHSR. 2014;4(5):193-201.

[14]. Sasson C, Rogers MA, Dahl J, Kellermann AL. Predictors of survival from out-of-hospital cardiac arrest: a systematic review and meta-analysis. CircCardiovascQual Outcomes. 2010;3(1);63-81.

[15]. Rajapakse R, Noè M, Kersnik J. Public knowledge of cardiopulmonary resuscitation in Republic of Slovenia. Wien KlinWochenschr. 2010;122(1):667-72.

[16]. Kuramoto N, Morimoto T, Kubota Y, Maeda Y, Seki S, Takada K, et al. Public perception of and willingness to perform bystander CPR in Japan. Resuscitation. 2008;79:475-81.

[17]. Marco CA, Schears RM. Societal opinions regarding CPR. Am J Emerg Med. 2002;20:207-11.

[18]. Chandrasekaran S, Kumar S, Bhat SA, Saravanakumar, Shabbir PM, Chandrasekaran V. Awareness of basic life support among medical, dental, nursing students and doctors. Indian J Anaesth 2010;54(2):121-6.

[19]. Kumar H, Upadhya P, Ashok S, Chowdari A, Niranjan GM, Dinesh B, et al. A cross-sectional study on awareness and perception about basic life support/ cardio pulmonary resuscitation among undergraduate medical students from coastal South India. IJMPH 2013;3(3):146-50.

[20]. Zaheer H, Haque Z. Awareness about BLS (CPR) among medical students: status and requirements. J Pak Med Assoc 2009;59(1):57-9.

[21]. Ralapanawa DM, Jayawickreme KP, Ekanayake EM, Kumarasiri PV. A study on the knowledge and attitudes on advanced life support among medical students and medical officers in a tertiary care hospital in Sri Lanka. BMC Res Notes 2016;19(1): 462-8.

[22]. Ravari H, Abrishami M, Ghezel-Sofla M, Mohammad VS, Abrishami M.

[23]. Knowledge of Iranian Medical Interns Regarding Cardio-Pulmonary Resuscitation. Trauma Mon 2012;17(1):242-4.

[24]. Alanazi A, Hotan B, Alqahtani M, Alhalyabah, Alanazi A, Al-oraibi S. Community Awareness about Cardiopulmonary Resuscitation among Secondary School Students in Riyadh. World Journal of Medical Sciences 2013;8(3):186-9.

DOI: $10.9790 / 0853-1601072630 \quad$ www.iosrjournals.org 30 Page

